\title{
Epoxy Thermosets with Self-Healing Ability
}

\author{
Eugenio Amendola1, Stefania Dello Iacono', Antonello Pastore1, Massimiliano Curcio², \\ Maddalena Giordano ${ }^{2}$, Alfonso Iadonisi ${ }^{3}$ \\ ${ }^{1}$ National Research Council (CNR), Institute for Polymers, Composites and Biomaterials (IPCB), Portici, Italy \\ ${ }^{2}$ University of St. Andrews, St. Andrews, UK \\ ${ }^{3}$ Department of Chemical Sciences, University of Naples "Federico II", Napoli, Italy \\ Email: *eugenio.amendola@cnr.it
}

Received 10 June 2015; accepted 9 July 2015; published 16 July 2015

\begin{abstract}
A hybrid epoxy resin with intrinsic self healing properties has been prepared from a bifunctional Diels-Alder (DA) adduct. The obtained network, based on conventional Diglycidyl ether of BisphenolA (DGEBA) and DA epoxy, leads to simultaneous tuning of physical-chemical properties and healing capability. The self-repairing behavior has been verified by means of scratch recovery observation and micromechanical analysis. A satisfactory morphological and mechanical recovery has been achieved by thermal stimulus, leading to very promising application in the field of adhesives and structural applications.
\end{abstract}

\section{Keywords}

Diels-Alder, Self-Healing, Epoxy Resin, Scratch Recovery, Nanoindentation

\section{Introduction}

Self-healing polymers are a class of smart materials able to recover after sustaining damage. While the first example of self-healing process relied on monomer-filled beads dispersed throughout the polymer matrix [1], a more innovative approach makes use of the Diels-Alder (DA) reaction. DA adducts can be incorporated directly in the matrix backbone as functionalities on the uncured monomers. In such a way, the cured resin overcomes the single-use limitation of the composites and undergoes multiple temperature-dependent healing cycles. This strategy was initially proposed by Chen et al. [2], who synthesized highly crosslinked polymers through formation of interchain furan-maleimide DA adducts. Subsequently, several research groups have contributed to this topic, resulting in a range of originally synthesized materials such as polymers [3]-[7], copolymers [8] and polymeric coatings [9]. In addition to these, self-mendable epoxy resins have been extensively studied due to the possibility to implement epoxy functionalities on the furan moiety. Through this pathway it is possible to customize the polymer properties by modifying the DA precursor and/or the curing agent. Also in this case, typical DA adducts are composed of furan-maleimide dimers, linked together by a phenyl-derived spacer. The furan moiety can contain either two or four epoxide functionalities [10]-[14] crosslinked with anhydrides or polyamines. Moreover, in recent manuscripts, Van Assche et al. have employed oligoether-spaced terminal diamines

*Corresponding author.

How to cite this paper: Amendola, E., lacono, S.D., Pastore, A., Curcio, M., Giordano, M. and Iadonisi, A. (2015) Epoxy Thermosets with Self-Healing Ability. Journal of Materials Science and Chemical Engineering, 3, 162-167. 
as curing agents, which determined dramatic variations in the $T_{g}$ [15]-[17].

A detailed screening of systems composed by differently formulated networks is still lacking. The vast majority of these works has, as a common theme, the synthesis and characterization of samples based on unique composition. Based on such premises, herein we present the synthesis and characterization of a selected sample of epoxy resins capable of good to excellent scratch damage self-healing recovery. A more comprehensive study addressing correlations obtained changing different molecular features will be discussed elsewhere.

\section{Experimental}

\subsection{Synthesis and Materials}

Epichlorohydrin, furfuryl alcohol, tetrabutylammonium bromide, 1,1'methylenedi-4,1-phenylene-bismaleimmide, 4,4'-Diaminodiphenylmethane (DDM), O,O'-Bis(2-aminopropyl) polypropylene glycol-block-polyethylene glycol-block-polypropylene glycol (Jeff 500) with relative molecular mass approximately $600\left(M_{r}-600\right)$ were purchased from Sigma Aldrich and used as received. DGEBA with an Epoxy Equivalent Weight of 185 $190 \mathrm{~g} / \mathrm{eq}$ was kindly supplied by Elantas S.p.A. with commercial name of EC01.

Glycidyl furfuryl etherwas prepared according to the procedure proposed by de Almeida [18].

In order to synthesize the 2Ph2Epo DA adduct (Scheme 1), 1,1'methylenedi-4,1-phenylene-bismaleimmide (31.1 mmol) was dissolved in chloroform $(10-12 \mathrm{ml})$ in a $250 \mathrm{ml}$ round-bottom flask equipped with a condenser. Glycidyl furfuryl ether (2.5 Equation $77.8 \mathrm{mmol}$ ) was added to the solution and the flask was heated to $70^{\circ} \mathrm{C}$. The progress of the reaction was monitored by thin layer chromatography (TLC) and the reaction mixture was kept under stirring at $70^{\circ} \mathrm{C}$ for $12 \mathrm{~h}$. Afterflash column chromatography on silica gel using 8/2 chloroform/acetonitrile mixture as eluent, 2Ph2Epo product was isolated in 96\% yield.

The epoxy compound, containing both 2Ph2Epo DA adduct and DGEBA, was crosslinked using DDM and Jeff 500 as curing agents (Figure 1), insuitably defined proportions.

In order to develop materials with robust self-healing ability, the coexistence of a stable polymeric network and a thermoreversible one is required for the formation of a hybrid polymer architecture.

The former is obtained by the crosslinking of bifunctional DGEBA with tetrafunctional amines, while the latter is produced through the nucleophilic attack of the same curing agents on 2Ph2Epo. Due to complete compatibility and miscibility of 2Ph2Epo with DGEBA, both contributions to the network are simultaneously present in the homogeneous resin.

The epoxy and amine groups have been stoichiometrically balanced and reaction performed at $90^{\circ} \mathrm{C}$ for 24 hours in order to achieve complete conversion.

\subsection{Techniques}

Synthesized epoxy adduct 2Ph2Epo was analyzed by ${ }^{1} \mathrm{HNMR}$, recorded in $\mathrm{CDCl}_{3}$ with a Bruker $400 \mathrm{MHz}$ spectrometer.

Thermal properties were investigated: thermogravimetric analysis (TGA) was carried out using Q5000 TA Instrumets with nitrogen purge at $10^{\circ} \mathrm{C} / \mathrm{min}$, while differential scanning calorimetry (DSC) was performed with Q1000 TA Instruments, in the presence of nitrogen purge at $10^{\circ} \mathrm{C} / \mathrm{min}$.<smiles>CCN(C(C)=O)c1ccc(Cc2ccc(N3C(=O)C=CC3=O)cc2)cc1</smiles>
$+2$<smiles>c1coc(COCC2CO2)c1</smiles>

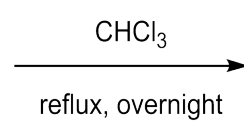<smiles>O=C1C2C3C=CC(COCC4CO4)(C3)C2C(=O)N1c1ccc(Cc2ccc(N3C(=O)C4C5C=CC(COCC6CO6)(O5)C4C3=O)cc2)cc1</smiles>

Scheme 1. Synthetic scheme for 2Ph2Epo DA adduct.<smiles>CC(C)(c1ccc(OCC2CO2)cc1)c1ccc(OCC2CO2)cc1</smiles><smiles>Nc1ccc(Cc2ccc(N)cc2)cc1</smiles><smiles>CC(N)C(C)OC(C)C(C)(C)OCC(C)(C)OCC(C)C(C)(C)N</smiles>

Figure 1. Additional resin components: DGEBA, DDM, Jeff 500. 
Elastic modulus $(E)$ was calculated from the load vs. displacement data. Nano Test ${ }^{\mathrm{TM}}$ Platform produced by Micro Materials Ltd has been used. This instrument monitors and records the dynamic load and displacement of a three-sided pyramidal diamond indenter Berkovich tip with a radius of about $100 \mathrm{~nm}$. All data were corrected for thermal drift and instrument compliance and subsequently analysed with the Oliver and Pharr method [19].

Elastic modulus was calculated by nanoindentation tests in load controlled mode: ten different indentation loads ranging from $50 \mathrm{mN}$ to $250 \mathrm{mN}$ were performed. At the maximum load a depth of about $6000 \mathrm{~nm}$ has to be measured, less than $10 \%$ of sample thickness (about $500 \mu \mathrm{m}$ ), in order to avoid the substrate interference.

The ability to recover scratch damage was evaluated by means of morphologicalanalysis. Optical microscopy was performed by Olympus BX 51M, equipped with Linkam THM600 hot stage.

\section{Results and Discussion}

As already discussed in the scientific literature [2]-[9], the presence of thermo-reversible DA adducts allows healing of mechanical damages. Healing mechanism is intrinsically associated to the presence of diene and dienophile pairs, either in-situ spontaneously generated during damage or produced by suitable temperature treatment above the $r$-DA temperature, and it can be repeated multiple times on the same location. Therefore, the formulation of self healing thermosets represents a very powerful tool for mending small mechanical damages.

Keeping in mind requirements of compatibility with existing conventional epoxy and/or their processing technologies, a bifunctional DA epoxy has been synthesized and purified for subsequent curing. It is noteworthy to mention that the general approach described in literature consists in either the simultaneous DA formation and nucleophilic attack of amine onto epoxy [14], or preliminary reaction of amines with furfuryl glycidyl ether, followed by crosslinking with a proper bismaleimide [16].

The proposed 2Ph2Epo meets all previous requirements and can be mixed with DGEBA in all percentages and cured with a stoichiometric amount of amine(s). If epoxy resin is $100 \%$ composed of 2Ph2Epo DA adduct, self healing behavior is maximized and can be easily observed in the proper temperature range, but consequently, poor mechanical properties are determined. On the other hand, the lack of DA adducts in the mixture prevents any self-healing behavior and correspond to conventional formulations.

Aneasy approach can be used for the description of crosslinked resin during self healing [20]. The average functionality, $f$, depends only on monomers average functionality and mixture stoichiometric composition. As a general rule of thumb, if $f$ is smaller than 2, only branched oligomers are temporarily present, while $f$ exceeding 2 gives rise to crosslinked 3-D network. The average functionality, $f$, can be used to evaluate the actual molecular structure during heat treatments.

In our case, evaluation of $f$ for the pristine unreacted DA epoxy mixed with amine results into the value of 2.67, the same value observed for conventional bi-epoxides cured with tetra-functional amines, and therefore a 3-D network is obtained upon curing. In the event of $r$-DA reaction, triggered by mechanical damages [21] or temperature increase, the system composition changes, the DA epoxy reversibly transforms into a monofunctional component and $f$ drops to 1.60 , which is related to the "open" molecular framework. Hence, thermomechanical stability ( $T_{\mathrm{g}}$ and mechanical modulus) is reduced to a great extent.

Based on the previous assumptions, the best compromise between self-healing ability and physical-chemical properties has been achieved with 2Ph2Epo-DGEBA (65:35) + DDM-Jeff500 (60:40), containing an epoxy molar ratio of 65/35 between 2Ph2Epo and DGEBA. After preliminary screening for curing agent selection, based on $T_{\mathrm{g}}$ of resulting cured resins, a mixture of DDM and Jeff500 (60/40 by mol) has been adopted.

The 2Ph2Epo-DGEBA (65:35) + DDM-Jeff500 (60:40) mixture has been reacted at $90^{\circ} \mathrm{C}$ and the extent of curing monitored by DSC. At the end of crosslinking, $T_{\mathrm{g}}$ reaches the value of $88^{\circ} \mathrm{C}$ and no further residual reaction is observed during the first heating scan, as shown in Figure 2. At higher temperatures a broad endothermic phenomenon is observed during DSC scan at $123^{\circ} \mathrm{C}$, related to occurrence of $r$-DA reaction [21].

The formation of 2Ph2Epo adduct was confirmed by ${ }^{1} \mathrm{HNMR}$ spectroscopy. Peak at $\delta-5.5$, is correlated to the change of hybridization from $\mathrm{sp}^{2}$ to $\mathrm{sp}^{3}$ of $\alpha$-carbon atom deriving from furfuryl glycidyl ether. The presence of two stereoisomers, exo and endo, can be inferred, with the first overwhelming the second. Inversion of stereoisomers concentration after heating $2 \mathrm{Ph} 2 \mathrm{Epo}$ at $120^{\circ} \mathrm{C}$ and subsequent cooling to room temperature evidenced the occurrence of $r$-DA and DA recombination.

Nanoindentation has been used in order to investigate the elastic modulus of cured material and self-healing proprieties. The reduced elastic modulus, $E_{r}$, was calculated based on Equation (1), taking into account the effect of non-rigid indenter column: 


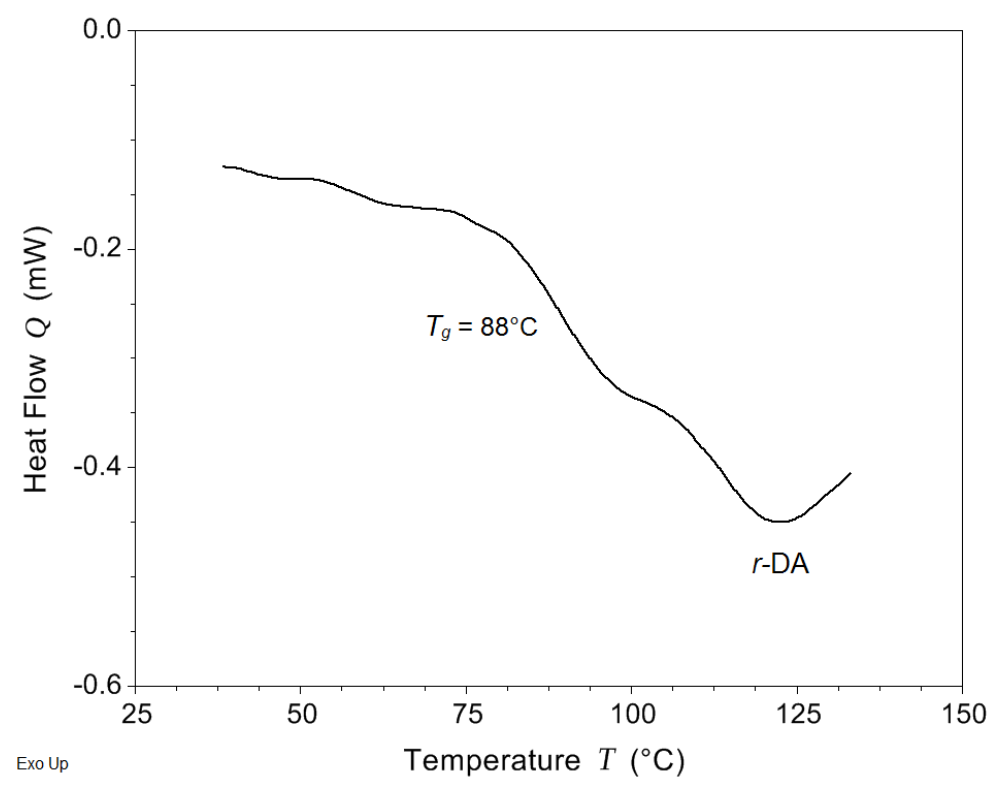

Figure 2. DSC scan of 2Ph2Epo-DGEBA (65:35) + DDM-Jeff500 (60:40) $10^{\circ} \mathrm{C} / \mathrm{min}$.

$$
\mathrm{E}_{\mathrm{r}}=\frac{\sqrt{\pi} \mathrm{S}}{2 \beta \sqrt{\mathrm{A}}}=\left(\frac{\left(1-v_{\mathrm{i}}^{2}\right)}{\mathrm{E}_{\mathrm{i}}}+\frac{\left(1-v_{\mathrm{s}}^{2}\right)}{\mathrm{E}_{\mathrm{s}}}\right)^{-1}
$$

where $\mathrm{A}$ is the contact area, $\beta$ the geometric constant (1.034 for a Berkovich indenter) and $\mathrm{S}$ the unloading stiffness at maximum load. $E$ and $v$ are the elastic modulus and the Poisson ratio; and the subscripts "i" and "s" refer to the diamond indenter and the specimen, respectively. The $E_{\mathrm{i}}$ is $1140 \mathrm{GPa}, v_{\mathrm{i}}$ is 0.07 and the $v_{\mathrm{s}}$ is 0.35 .

The tests were carried out on virgin 2Ph2Epo-DGEBA (65:35) + DDM-Jeff500 (60:40) sample, after thermal treatment at $120^{\circ} \mathrm{C}$ for 30 minutes and after a further thermal annealing at $90^{\circ} \mathrm{C}$ for 24 hours. In Table 1 measured values of reduced modulus and calculated elastic modulus are reported.

According to Zheng et al. [22] elastic modulus measured by depth sensing indentation could be invariantly higher than tensile test by a value of $5 \%-20 \%$.

The morphological assessment of self healing behavior has been observed by optical microscopy. A sharp razor blade has been used to produce fresh scratches on cured sample surface, and recovery behavior has been observed during heat treatment at $140^{\circ} \mathrm{C}$. TGA has been preliminary used to evaluate thermo-chemical stability of cured resin, identifying the onset of decomposition (3 weight \% loss) at $180^{\circ} \mathrm{C}$.

After recombination of scratch, as reported in Figure 3, healing cycle can be completed by thermal annealing at $90^{\circ} \mathrm{C}$. This additional treatment is necessary to accomplish the direct DA reaction and recombine the diene and dienophile generated during damage and/or heat treatment [21], introducing the additional beneficial effects of restoring elastic modulus to values similar to pristine resin (Table 1, $4.10 \mathrm{GPa} v \mathrm{~s} 4.89 \mathrm{GPa}$ ).

Comparison of results presented in Table $\mathbf{1}$ with images of Figure $\mathbf{3}$ documents the promising properties of the hybrid synthesized epoxy self healing material.

\section{Conclusions}

A hybrid epoxy resin with intrinsic self healing properties has been prepared from bifunctional 2Ph2Epo DielsAlder adduct.

A suitable mixture of 2Ph2Epo and DGEBA has been cured with DDM and Jeff500 amines, leading to simultaneous tuning of physical-chemical properties and healing capability. The presence of conventional epoxy, in addition to the thermoreversible DA adducts, improved thermal and mechanical stability at expenses of selfhealing features. Therefore, a careful balance has to be achieved during resin formulation. To allow damage 


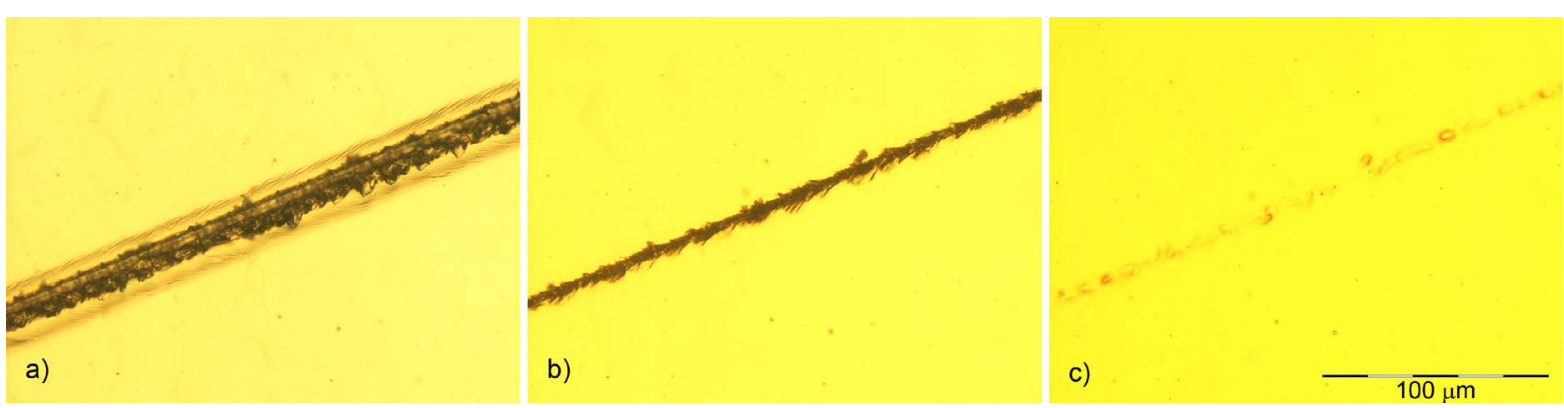

Figure 3. Optical images of 2Ph2Epo-DGEBA (65:35) + DDM-Jeff500 (60:40). (a) Scratched sample; (b) Partially healed at $140^{\circ} \mathrm{C}$ for $5 \mathrm{~min}$; (c) healed at $140^{\circ} \mathrm{C}$ for $25 \mathrm{~min}$.

Table 1. Reduced modulus [GPa] and elastic modulus [GPa] of 2Ph2Epo-DGEBA (65:35) + DDM-Jeff500 (60:40).

\begin{tabular}{ccc}
\hline Sample & \multicolumn{2}{c}{ Nanoindentetion test } \\
\cline { 2 - 3 } & Reduced modulus [GPa] & Elastic modulus [GPa] \\
\hline As prepared & 5.55 & 4.89 \\
Heat-treatment @ $120^{\circ} \mathrm{C}, 30 \mathrm{~min}$ & 2.96 & 2.60 \\
Additional heat-treatment @ $90^{\circ} \mathrm{C}, 24 \mathrm{~h}$ & 4.65 & 4.10 \\
\hline
\end{tabular}

recovery, glass transition temperature of cured resin was tailored according to DA reaction temperature range.

The presence of Diels-Alder adducts in the network main-frame determines intrinsic healing ability triggered by thermal stimuli. A main advantage related to this class of functional materials is the capability of multiple healing, where damage should occur in the same location several times.

The intrinsic recovery mechanism is based on the formation of suitable functional groups, diene and dienophile, generated in-situ as a result of mechanical stresses. To improve the local molecular mobility and consequently the healing efficiency, a further thermal stimulus is applied to trigger the $r$-DA reaction. The macroscopic damages are healed during this preliminary stage.

But the resulting material is characterized by a less dense network, with decreased overall mechanical properties.

Thus, the thermal treatment is completed by a lower temperature annealing $\left(90^{\circ} \mathrm{C}\right)$, suitable to induce the network reconfiguration through the direct DA recombination.

Performance of cured epoxy has been evaluated by scratch recovery analysis and micromechanical (nanindentation) tests on pristine sample and after complete thermal treatments.

A satisfactory morphological and mechanical recovery has been achieved leading to very promising application in the field of adhesives, coatings and structural applications.

\section{Acknowledgements}

The activities were performed in the frame of the projects "A Life-cycle Autonomous Modular System for Aircraft Material State Evaluation and Restoring System-ALAMSA, FP7 Grant Agreement 314768”.

\section{References}

[1] White, S.R., Sottos, N.R., Geubelle, P.H., Moore, J.S., Kessler, M.R., Sriram, S.R., Brown, E.R. and Viswanathan, S. (2001) Autonomic Healing of Polymer Composites. Nature, 409, 794-797. http://dx.doi.org/10.1038/35057232

[2] Chen, X., Dam, M.A., Ono, K., Mal, A., Shen, H., Nutt, S.R., Sheran, K. and Wudl, F. (2002) A Thermally ReMendable Cross-Linked Polymeric Material. Science, 295, 1698-1702. http://dx.doi.org/10.1126/science.1065879

[3] Liu, Y.-L., Hsieh, C.-Y. and Chen, Y.-W. (2006) Thermally Reversible Cross-Linked Polyamides and Thermo-Responsive Gels by Means of Diels-Alder Reaction. Polymer, 47, 2581-2586. http://dx.doi.org/10.1016/j.polymer.2006.02.057

[4] Gaina, C., Ursache, O. and Gaina, V. (2011) Re-Mendable Polyurethanes. Polymer-Plastics Technology and Engi- 
neering, 50, 712-718. http://dx.doi.org/10.1080/03602559.2010.551392

[5] Toncelli, C., De Reus, D.C., Picchioni, F. and Broekhuis, A.A. (2012) Properties of Reversible Diels-Alder Furan/ Maleimide Polymer Networks as Function of Crosslink Density. Macromolecular Chemistry and Physics, 213, 157165. http://dx.doi.org/10.1002/macp.201100405

[6] Gaina, C., Ursache, O., Gaina, V. and Varganici, C.D. (2013) Thermally Reversible Cross-Linked Poly(Ether-Urethane)s. Express Polymer Letters, 7, 636-650. http://dx.doi.org/10.3144/expresspolymlett.2013.60

[7] Barthel, M.J., Rudolph, T., Teichler, A., Paulus, R.M., Vitz, J., Hoeppener, S., Hager, M.D., Schacher, F.H. and Schubert, U.S. (2013) Self-Healing Materials via Reversible Crosslinking of Poly(Ethylene Oxide)-Block-Poly(Furfuryl Glycidyl Ether) (PEO-b-PFGE) Block Copolymer Films. Advanced Functional Materials, 23, 4921-4932. http://dx.doi.org/10.1002/adfm.201300469

[8] Kavitha, A.A. and Singha, N.K. (2010) Smart “All Acrylate” ABA Triblock Copolymer Bearing Reactive Functionality via Atom Transfer Radical Polymerization (ATRP): Demonstration of a “Click Reaction” in Thermoreversible Property. Macromolecules, 43, 3193-3205. http://dx.doi.org/10.1021/ma902203r

[9] Postiglione, G., Turri, S. and Levi, M. (2015) Effect of the Plasticizer on the Self-Healing Properties of a Polymer Coating Based on the Thermoreversible Diels-Alder Reaction. Progress in Organic Coatings, 78, 526-531. http://dx.doi.org/10.1016/j.porgcoat.2014.05.022

[10] Peterson, A.M., Jensen, R.E. and Palmese, G.R. (2010) Room-Temperature Healing of a Thermosetting Polymer Using the Diels-Alder Reaction. ACS Applied Materials Interfaces, 2, 1141-1149. http://dx.doi.org/10.1021/am9009378

[11] Pratama, P.A., Sharifi, M., Peterson, A.M. and Palmese, G.R. (2013) Room Temperature Self-Healing Thermoset Based on the Diels-Alder Reaction. ACS Applied Materials Interfaces, 5, 12425-12431. http://dx.doi.org/10.1021/am403459e

[12] Pratama, P.A., Peterson, A.M. and Palmese, G.R. (2013) The Role of Maleimide Structure in the Healing of FuranFunctionalized Epoxy-Amine Thermosets. Polymer Chemistry, 4, 5000-5006. http://dx.doi.org/10.1039/c3py00084b

[13] Zhang, W., Duchet, J. and Gérard, J.F. (2014) Self-Healable Interfaces Based on Thermo-Reversible Diels-Alder Reactions in Carbon Fiber Reinforced Composites. Journal of Colloid and Interface Science, 430, 61-68. http://dx.doi.org/10.1016/j.jcis.2014.05.007

[14] Tian, Q., Yuan, Y.C., Rong, M.Z. and Zhang, M.Q. (2009) A Thermally Remendable Epoxy Resin. Journal of Materials Chemistry, 19, 1289-1296. http://dx.doi.org/10.1039/b811938d

[15] Scheltjens, G., Brancert, J., De Graeve, I., Van Mele, B., Terryn, H. and Van Assche, G. (2011) Self-Healing Property Characterization of Reversible Thermoset Coatings. Journal of Thermal Analysis and Calorimetry, 105, 805-809. http://dx.doi.org/10.1007/s10973-011-1381-4

[16] Scheltjens, G., Diaz, M.M., Brancart, J., Van Assche, G. and Van Mele, B. (2013) A Self-Healing Polymer Network Based on Reversible Covalent Bonding. Reactive and Functional Polymers, 73, 413-420. http://dx.doi.org/10.1016/j.reactfunctpolym.2012.06.017

[17] Brancart, J., Scheltjens, G., Muselle, T., Van Mele, B., Terryn, H. and Van Assche, G. (2014) Atomic Force Microscopy-Based Study of Self-Healing Coatings Based on Reversible Polymer Network Systems. Journal of Intelligent Material Systems and Structures, 25, 40-46. http://dx.doi.org/10.1177/1045389X12457100

[18] de Almeida, C.G., Reis, S.G., de Almeida, A.M., Diniz, C.G., da Silva, V.L. and le Hyaric, M. (2011) Synthesis and Antibacterial Activity of Aromatic and Heteroaromatic Amino Alcohols. Chemical Biology Drug Design, 78, 876-880. http://dx.doi.org/10.1111/j.1747-0285.2011.01231.x

[19] Oliver, W.C. and Pharr, G.M. (1992) An Improved Technique for Determining Hardness and Elastic-Modulus Using Load and Displacement Sensing Indentation Experiments. Journal of Materials Research, 7, 1564-1583. http://dx.doi.org/10.1557/JMR.1992.1564

[20] Odian, G. (2004) Principles of Polymerization. 4th Edition, John Wiley \& Sons Ltd., Chichester. http://dx.doi.org/10.1002/047147875X

[21] Heo, Y. and Sodano, H.A. (2014) Self-Healing Polyurethanes with Shape Recovery. Advanced Functional Materials, 24, 5261-5268. http://dx.doi.org/10.1002/adfm.201400299

[22] Zheng, S. and Ashcroft, I.A. (2005) A Depth Sensing Indentation Study of the Hardness and Modulus of Adhesives. International Journal of Adhesion and Adhesives, 25, 67-76. http://dx.doi.org/10.1016/j.ijadhadh.2004.02.004 